appealing option, yet they may be too limited in flow and durability. ${ }^{2}$ The AA-LVAD combines the benefit of a relatively quick insertion with sufficient circulatory support for restoration of end-organ function ${ }^{4}$ and avoids the hazards of resternotomy and invasive surgery.

\section{References}

1. Werdan K, Gielen S, Ebelt H, Hochman JS. Mechanical circulatory support in cardiogenic shock. Eur Heart J. 2014;35:156-67.
2. Ziemba EA, John R. Mechanical circulatory support for bridge to decision: which device and when to decide. J Card Surg. 2010;25:425-33.

3. Takayama H, Naka Y, Jorde UP, Stewart AS. Less invasive left ventricular assist device placement for difficult resternotomy. J Thorac Cardiovasc Surg. 2010;140: 932-3

4. Akay MH, Gregoric ID, Radovancevic R, Cohn WE, Frazier OH. Timely use of a CentriMag heart assist device improves survival in postcardiotomy cardiogenic shock. J Card Surg. 2011;26:548-52.

5. Rao V, Oz MC, Flannery MA, Catanese KA, Argenziano M, Naka Y. Revised screening scale to predict survival after insertion of a left ventricular assist device. J Thorac Cardiovasc Surg. 2003;125:855-62.

\title{
Are preoperative B-type natriuretic peptide levels associated with outcome after pulmonary artery banding and the double switch operation in patients with congenitally corrected transposition of the great arteries: A pilot study
}

\author{
Danton S. Char, MD, ${ }^{a}$ Stephen C. Shiboski, PhD, ${ }^{b}$ Frank L. Hanley, MD,${ }^{c}$ and Jeffrey R. Fineman, MD, ${ }^{d}$ \\ Stanford and San Francisco, Calif
}

Pulmonary artery banding (PAB) for ventricular training followed by the double switch operation (DSO) is an attractive surgical option for suitable patients with congenitally corrected transposition of the great arteries (ccTGA). After repair, the systemic circulation is supported by the morphologic left ventricle (LV). Adoption of DSO was driven by the poor natural history of the systemic right ventricle (RV) and successful outcomes with DSO have been reported since the mid-1990s. ${ }^{1}$ Although mortality after these operations is low with careful patient selection, the accurate prediction of adverse postoperative outcomes is difficult, and there remains an unpredictable risk of morbidity, takedown or reoperation. ${ }^{2}$

Recent studies have demonstrated that perioperative changes in B-type natriuretic peptide (BNP) levels may

\footnotetext{
From the Division of Pediatric Anesthesia, ${ }^{a}$ Department of Anesthesiology, Stanford University School of Medicine, Stanford, Calif; Department of Epidemiology and Biostatistics, ${ }^{\text {b }}$ University of California, San Francisco, Calif; Pediatric Heart Center, ${ }^{c}$ Lucile Packard Children's Hospital, Stanford University School of Medicine, Stanford, Calif; and Division of Pediatric Critical Care Medicine, ${ }^{d}$ Department of Pediatrics, University of California, San Francisco, Calif.

This study was made possible by funding from the Pediatric Heart Center Research Program, Lucile Packard Foundation for Children's Health, Stanford CTSA (grant number UL1 RR025744).

Disclosures: Authors have nothing to disclose with regard to commercial support.

Received for publication April 17, 2014; revisions received June 17, 2014; accepted for publication July 7, 2014; available ahead of print Aug 16, 2014.

Address for reprints: Danton S. Char, MD, Department of Anesthesiology, H3580, Stanford University Medical Center, 300 Pasteur Drive, Stanford, CA 94305 (E-mail: dchar@stanford.edu).

J Thorac Cardiovasc Surg 2014;148:2434-6

$0022-5223 / \$ 36.00$

Copyright (c) 2014 by The American Association for Thoracic Surgery

http://dx.doi.org/10.1016/j.jtcvs.2014.07.003
}

predict postoperative morbidity and mortality after surgery for the repair or palliation of congenital cardiac defects. However, the potential usefulness of preoperative BNP levels as predictors of postoperative outcomes in patients undergoing repair for ccTGA has not been investigated.

This pilot study hypothesized that preoperative BNP levels could be associated with unexpected outcomes after PAB and DSO in patients otherwise deemed to be suitable operative candidates on the basis of standard preoperative clinical, echocardiographic, and hemodynamic assessments.

\section{MATERIALS AND METHODS \\ Design and Participants}

A pilot prospective cohort study was undertaken at Lucile Packard Children's Hospital Heart Center from November 2011 to November 2013. Eligible participants included all patients with ccTGA undergoing either PAB or DSO. Management followed standard institutional practices. Informed consent from the patients or their guardians was obtained before enrollment. The Stanford University Medical Center Institutional Review Board approved the study (IRB 22458).

Blood samples were obtained from a venous or arterial catheter less than 24 hours preoperatively and were assayed using a commercially available fluorescence immunoassay (Triage Meter Plus; Biosite Diagnostic, San Diego, Calif).

\section{Outcome}

The end point was a composite of adverse outcomes including death, cardiac arrest, need for extracorporeal cardiopulmonary life support or emergency reoperation.

\section{Analysis}

The 2-sided Fisher exact test was used to evaluate the association between increased BNP level $(>300 \mathrm{pg} / \mathrm{mL})$ and the binary composite 
TABLE 1. Demographics, preoperative BNP, and outcomes

\begin{tabular}{|c|c|c|c|c|c|}
\hline Age & Weight (kg) & Diagnosis & Surgery performed & $\begin{array}{l}\text { Preoperative } \\
\text { BNP }(\mathrm{pg} / \mathrm{mL})\end{array}$ & Outcome \\
\hline $24 \mathrm{y}$ & 73.6 & $\begin{array}{l}\text { ccTGA, dextroversion after VSD } \\
\text { closure, } \\
\text { and TV replacement }\end{array}$ & PAB & 48.1 & \\
\hline $3 \mathrm{y}$ & 11.2 & $\begin{array}{l}\text { ccTGA, displastic ebsteinoid TV } \\
\text { with severe TR, } \\
\text { and LV dilation }\end{array}$ & $\mathrm{PAB}$ & 366 & $\begin{array}{l}\text { Emergency reoperation } \\
\text { PAB loosening }\end{array}$ \\
\hline $15 \mathrm{y}$ & 66.5 & ccTGA and PFO & $\mathrm{PAB}$ & 17.7 & \\
\hline 14 mo & 10.7 & $\begin{array}{l}\text { Situs inversus, ccTGA with } \\
\text { pulmonary atresia }\end{array}$ & Bidirectional Glenn & 14.9 & \\
\hline $36 \mathrm{y}$ & 90.5 & ccTGA, VSD & PAB; conduit change & 26.1 & \\
\hline $14 \mathrm{y}$ & 60.6 & ccTGA & Transplant & 94.5 & \\
\hline $7 \mathrm{mo}$ & 8.1 & ccTGA, severe TR & $\mathrm{PAB}$ & 331 & Cardiac arrest \\
\hline $16 \mathrm{mo}$ & 9.4 & $\begin{array}{l}\text { ccTGA, subpulmonic stenosis, } \\
\text { large VSD }\end{array}$ & DSO & 8.3 & \\
\hline $4 y$ & 12.7 & $\begin{array}{l}\text { ccTGA, displastic ebsteinoid TV } \\
\text { with severe TR, } \\
\text { and LV dilation }\end{array}$ & DSO & 102 & \\
\hline $6 y$ & 20.9 & ccTGA, prior $\mathrm{PAB}$ & DSO & 18.5 & \\
\hline $18 \mathrm{mo}$ & 12.4 & ccTGA, VSD & DSO & 34.2 & \\
\hline $16 \mathrm{y}$ & 72.1 & ccTGA prior $\mathrm{PAB}$ & PAB & 11.5 & \\
\hline $6 \mathrm{y}$ & 20 & ccTGA, prior PAB & DSO & 38.1 & \\
\hline
\end{tabular}

$B N P$, B-type natriuretic peptide; $c c T G A$, congenitally corrected transposition of the great arteries; $V S D$, ventricular septal defect; $T V$, tricuspid valve; $P A B$, pulmonary artery banding; $T R$, tricuspid regurgitation; $L V$, left ventricle; $P F O$, patent foramen ovale; $D S O$, double switch operation.

adverse outcome. Exact logistic regression was used to estimate the corresponding odds ratio and $95 \%$ confidence interval. Statistical analyses were performed using Stata 13 (StataCorp LP, College Station, Tex).

\section{RESULTS}

Fifteen patients were approached and 13 were enrolled. Six patients underwent PAB and 5 underwent DSO. Two patients were excluded from the analysis: 1 who underwent a Glenn operation and 1 who underwent transplantation (Table 1).

Two patients experienced an adverse outcome: 1 developed severe hypotension requiring emergency reoperation

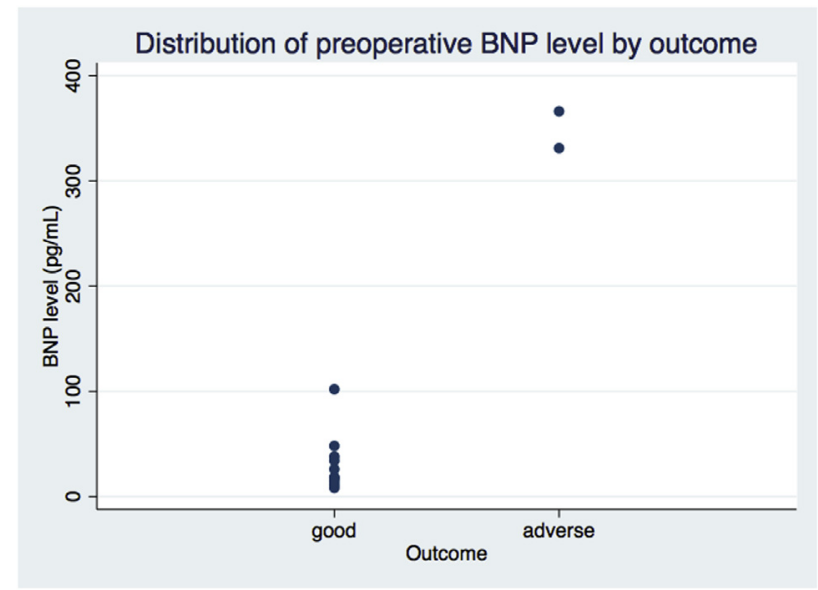

FIGURE 1. Distribution of preoperative BNP level (pg/mL) by outcome. $B N P$, B-type natriuretic peptide. to loosen the pulmonary artery (PA) band; 1 had an intraoperative cardiac arrest, treated successfully with resuscitation measures. None of the patients died. Both adverse outcomes were in patients undergoing PAB.

Preoperative BNP levels ranged from 8.3 to $366 \mathrm{pg} / \mathrm{mL}$. The 2 patients with adverse outcome had preoperative BNP levels of $366 \mathrm{pg} / \mathrm{mL}$ and $331 \mathrm{pg} / \mathrm{mL}$. All other patients had preoperative BNP levels less than $102 \mathrm{pg} / \mathrm{mL}$. BNP was strongly associated with adverse outcome, particularly BNP greater than $300 \mathrm{pg} / \mathrm{mL}$ (Figure 1). All patients met criteria for morphologic LV readiness for DSO or need for further retraining by $\mathrm{PAB}$ by clinical evaluation, assessment of LV ejection fraction and degree of mitral regurgitation measured by echocardiography, LV mass measured by magnetic resonance imaging (MRI), and peak systolic and end diastolic LV pressures measured at cardiac catheterization.

The observed association between preoperative BNP greater than $300 \mathrm{pg} / \mathrm{mL}$ and adverse outcome was statistically significant $(P=.015)$. The corresponding exact odds ratio was 22 , with a $95 \%$ confidence interval of 1.36 to infinity. We were unable to adjust the analysis for heterogeneity by age, weight, gender, or differences in cardiac disease.

\section{DISCUSSION}

Outcomes after PAB and DSO in patients with ccTGA have continued to improve since the introduction of the repair. However, the incidence of in-hospital mortality 
remains high, with recent estimates ranging from $2 \%$ to $10 \%{ }^{2}$ In this pilot study, we found that preoperative BNP levels were markedly higher in patients with adverse outcomes than in patients with good outcomes in a sample of patients all thought to be good candidates for surgery by the current standard preoperative evaluations by cardiac catheterization, echocardiography, and MRI. Morphologic LV readiness for DSO or need for further retraining by PAB was based on 5 criteria at our institution: LV ejection fraction and degree of mitral regurgitation measured by echocardiography, LV mass measured by MRI, and peak systolic and end diastolic LV pressures measured at cardiac catheterization. Other institutions use similar but not exactly the same criteria. ${ }^{2,4}$ Intraoperative PAB tightening is guided by simultaneous echocardiography and LV and systemic pressure measurements. A midline sternotomy is performed to expose the aorta and PA. Minimal dissection is performed to encircle the proximal main PA with a silicone rubber band (Dow Corning, Midland, Mich). The degree of band tightening is guided by simultaneous transesophageal echocardiographic analysis and direct proximal PA pressure, LV pressure, and central venous pressure (CVP, a marker of LV end diastolic pressure) measurement. As the band is tightened to achieve successively higher pressures, the LV is monitored for diminished systolic function. As the LV pressure increases, transesophageal echocardiographic analysis demonstrates shift of the intraventricular septum. Often we see a decrease in tricuspid regurgitation. The goal after PAB is to get to $100 \%$ systemic pressure in the LV, however we rarely achieve this. We usually achieve approximately $60 \%$ of systemic pressure with our first banding procedure. Frequently, if we go beyond $60 \%$ we see evidence of LV strain and decreased function as determined by (1) decreased shortening fraction; (2) mitral regurgitation; (3) increased CVP (a proxy for LV end diastolic pressure); (4) arrhythmias. If any of these develop, we reduce the tightness of the PAB until these resolve.

BNP has emerged as a powerful biomarker of impaired myocardial performance. Landmark studies in adults demonstrate a cutoff of $100 \mathrm{pg} / \mathrm{mL}$ for the diagnosis of congestive heart failure. ${ }^{5}$ Levels in congenital heart disease are much more diverse, and are likely both age and defect specific. We found that in ccTGA, a BNP level greater than $300 \mathrm{pg} / \mathrm{mL}$ was highly associated with an adverse outcome, although where the exact cutoff level lies will require further investigation. This is a meaningful finding because the exact preoperative hemodynamics that predict postoperative adverse outcomes in ccTGA remain elusive and suggest that measurement of BNP blood levels may be an important adjunct to the current preoperative evaluation.

The authors gratefully acknowledge Dr Chandra Ramamoorthy's support in pursuing this project.

\section{References}

1. Reddy VM, McElhinney DB, Silverman NH, Hanley FL. The double switch procedure for anatomic repair of congenitally corrected transposition of the great arteries in infants and children. Eur Heart J. 1997;18:1470-7.

2. Malhotra SP, Reddy VM, Qui M, Pirolli TJ, Barboza L, Reinhartz O, et al. The hemi-Mustard/bidirectional Glenn atrial switch procedure in the double-switch operation for congenitally corrected transposition of the great arteries: rationale and midterm results. J Thorac Cardiovasc Surg. 2011;141: 162-70.

3. Radman M, Keller RL, Oishi P, Datar SA, Wellnitz K, Azakie A, et al. Preoperative B-type natriuretic peptide levels are associated with outcome after total cavopulmonary connection (Fontan). J Thorac Cardiovasc Surg. 2014;148: 212-9.

4. Ly M, Belli E, Leobon B, Kortas C, Grollmüss OE, Piot D, et al. Results of the double switch operation for congenitally corrected transposition of the great arteries. Eur J Cardiothorac Surg. 2009;35:879-83.

5. Maisel AS, Krishnaswamy P, Nowak RM, McCord J, Hollander JE, Duc P, et al. Rapid measurement of B-type natriuretic peptide in the emergency diagnosis of heart failure. N Engl J Med. 2002;347:161-7. 